\title{
Outcomes of Professional Development Activities for Selected Texas School Personnel Helping Students Cope with Behavioral and Mental Health Issues
}

Gary Wingenbach ( $\nabla$ wingenbach@tamu.edu )

Texas A\&M University

\section{Taniya Koswatta}

Texas A\&M University

Josephine Engels

Mental Health of America of Greater Houston

Jamie Freeny

Mental Health of America of Greater Houston

Sana Haddad

Mental Health of America of Greater Houston

\section{Research Article}

Keywords: School Personnel, Behavioral / Mental Health Training

Posted Date: February 15th, 2022

DOI: https://doi.org/10.21203/rs.3.rs-1318443/v1

License: (c) (i) This work is licensed under a Creative Commons Attribution 4.0 International License.

Read Full License 


\section{Abstract}

School personnel help youth cope with life and school stressors daily. However, help may depend on one's confidence or knowledge of such issues. In 2019 and 2020, more than 13,800 Texas educators participated in Emotional Backpack Project (EBP) training for youth coping with behavioral and mental health issues. Post-intervention results showed significant gains in understanding students' behavioral and mental health issues, improved confidence in approaching students, parents, or other school staff to discuss students' harmful behaviors, understanding mindfulness activities, and increased knowledge of trauma informed schools and trauma informed educators. Teachers and other school personnel were less confident approaching parents or guardians to discuss youth mental health issues than in approaching students, counselors, and other staff. EBP interventions produced positive results in school personnel's knowledge, perceptions, and confidence to help students cope with behavioral and mental health issues. EBP training should be adopted widely and occur more than once annually.

\section{Introduction}

Just five years ago, about $13 \%$ of age-standardized deaths were caused by intentional self-harm in the United States (World Health Organization, 2016). Twelve percent of Texas teenagers (compared to 7\% nationally) said they attempted suicide in 2017 ("Texas 2017 Results," Centers for Disease Control and Prevention, 2018). More alarming, $42 \%$ of LGBTQ (lesbian, gay, bisexual, transgender and queer or questioning) teens reported they had seriously considered suicide (Mclnerny, July 5, 2018). In 2018, Texas reported 12 teen (15-24 years old) deaths due to mental and/or behavioral health disorders (Centers for Disease Control and Prevention, 2018). It is evident that Texan teenagers experience increased stress and anxiety in their personal lives, which can affect their school lives.

Addressing students' behavioral and mental health issues became a Texas priority on May 18, 2018, because of school shootings in Santa Fe. Increasing life's stressors, many Santa Fe teens and their families were still repairing homes damaged from Hurricane Harvey, which struck just nine months before the school shootings (Martin, 2020). These instances illustrate the unpredictability of stressors, natural or man-made, and how they can affect youths' behavioral and mental health. The Texas Legislature acknowledged that more behavioral counseling with increased staffing was needed in Texas schools to address students' mental health needs. Similarly, "comprehensive training, informing students, parents and teachers how to relay information; identifying mental health challenges for students and helping respond to those challenges and get students the counseling they need; and mandated parent training" (Buchele, 2018) were included in strategies to stop school shootings.

Texan legislators' ideas included improved training and development for school personnel who help students cope with behavioral and mental health issues. Next to parents, teachers and other school personnel are early interveners for youth experiencing mental health problems or crises. Kern et al. (2017) noted "evidence suggests that school-based mental health services (SBMHS) have the highest likelihood 
of reaching youth in need" (p. 205). However, we wondered if educators were prepared adequately to help students with behavioral and mental health needs.

Identifying educators' training needs in student mental health can be found by evaluating their knowledge and perspectives of students' trauma and stressors. Reker (2016) found a need for appropriate traumaspecific training across educators' careers (e.g., early to late) and school types (e.g., elementary to secondary) for Nebraska teachers supporting students with childhood traumatic stress. Moon et al. (2017) found educators' top training needs were [knowledge] of mental health disorders, behavior management, and social skills. Alternatively, Anderson et al. (2019) found limited evidence that training programs improved teachers' helping behavior or students' mental health but emphasized a need to measure teachers' perceptions of student mental health needs after training programs.

School-based mental health professionals and administrators were significantly more concerned about students' mental health than were teachers (Atkins et al., 2010; Barrett et al., 2013; Jensen et al., 2011), supporting the notion that school personnel are under-utilized in promoting positive behavioral and mental health in schools. A need exists to train school personnel in student behavioral and mental health.

School personnel may lack knowledge or confidence in identifying and addressing students' behavioral and mental health needs. Research shows that students exhibit greater wellbeing in school and life when social and emotional learning programs and practices are implemented in schools and classrooms (Schonert-Reichl, 2019). Evidence exists that school personnel can impact positively students' behavioral and mental health, after appropriate interventions and training. There is much evidence that school personnel gained knowledge of students' behavioral and mental health issues after interventions and training (Eustache et al., 2017; Kutcher et al., 2015; Wei \& Kutcher, 2014). Jorm et al. (2010) found South Australian teachers increased their knowledge and changed their beliefs about treatment of students' mental health issues after training. Similar knowledge gains occurred among Canadian teachers after a health literacy program (Carr et al., 2017), and among U.S. mental health professionals after training in suicide prevention (Sale et al., 2018).

The evaluation framework was based on Kirkpatrick and Kirkpatrick's (2006) four-level (i.e., Reaction, Learning, Behavior, and Results) evaluation model. Kirkpatrick's four-level approach is a popular model for evaluating learner outcomes in training programs (Frye \& Hemmer, 2012). Kirkpatrick's model does not account for intervening variables such as trainer's expertise or learner motivation or previous knowledge. Therefore, the results are confined solely to program participants. We applied the Learning level (i.e., learner outcomes) to measure changes in learners' perceptions and/or knowledge. Insufficient time prohibited assessing behavior (changes caused by learning) or results (long-term impact from behavior change).

The purpose of this study was to assess the Emotional Backpack Project (EBP) intervention outcomes for school personnel. Did a professional development program change school personnel's perceptions or knowledge of students' behavioral and mental health issues? The study objectives were to assess and 
determine if significant changes occurred in participants' perceptions of the EBP intervention, and participants' knowledge of selected EBP topics.

\section{Methods}

A longitudinal trend survey (Fraenkel et al., 2019) was used because it permits data collection at different points (to study changes in the variables of interest). Different samples from a population, whose members may change, are surveyed at different times in trend studies.

The Center for School Behavioral Health (CSBH) at Mental Health America of Greater Houston (MHAGH) provided more than 150 training sessions, using EBP interventions in selected Texas school districts from 2019 to 2020. A need for interventions arose from students' increased trauma from natural (i.e., Hurricane Harvey) and manmade (e.g., Santa Fe Texas school shootings) disasters. MHAGH's in person workshops were delivered in schools before the novel Coronavirus 2019 lockdown; some virtual workshops were delivered after March 2020. Three MHAGH training specialists led the workshops. Training methods included experiential activities such as role play simulation, problem solving scenarios, and small group discussion about youth mental health issues.

The EBP is a year-long, train-the-trainer program. Intervention topics were based on the EBP curricula for students' behavioral and mental health needs and included Children's Mental Health, Trauma Informed Classrooms, Youth Suicide Prevention, Trauma 102, and Self-Care and Mindfulness. MHAGH's train-thetrainer workshops lasted nine hours; training for school personnel was about 1.5 hours/topic. After EBP training, trainees teach and equip school staffs to support students and families with youth behavioral and mental health needs. Briefly, EBP intervention topics included:

- Children's Mental Health (CMH): defines mental health, symptoms of mental health disorders, and presents strategies for empathetic conversations.

- Trauma Informed Classrooms (TIC): examines the effects of trauma on brain development, creating trauma informed spaces, and addresses grief in childhood.

- Youth Suicide Prevention (YSP): presents myths and facts of suicide and intervention strategies for youth with suicidal ideation.

- Advanced Trauma (T102): strategies to create trauma informed classrooms and campuses, including impacts of cultural awareness, equity, and racial/historical trauma in the classroom.

- Self-Care and Mindfulness (SCM): addresses employee burnout, establishing achievable SMART goals, and developing self-care plans.

Participants included school personnel (i.e., teachers, principals, counselors), parents, and community members (i.e., child-serving agencies in school districts) (Table 1). All participants were affiliated with public or private schools. 
Table 1

Participants at Intervention Trainings (EBP Training), 2019-2020.

\begin{tabular}{|llll|}
\hline EBP Interventions (Topics) & $\mathbf{2 0 1 9}$ & $\mathbf{2 0 2 0}$ & Total \\
\hline Children's Mental Health (CMH) & 3,896 & 703 & 4,599 \\
\hline Trauma-Informed Classrooms (TIC) & 3,055 & 1,188 & 4,243 \\
\hline Youth Suicide Prevention (YSP) & 2,625 & 799 & 3,424 \\
\hline Trauma 102 (T102) & - & 727 & 727 \\
\hline Self-Care and Mindfulness (SCM) & 4 & 885 & 889 \\
\hline $\begin{array}{l}\text { Note. Participants represented 28 Texas public school districts, four charter school systems, seven } \\
\text { special needs schools, four private schools, 28 behavioral health providers, 26 community education } \\
\text { and advocacy groups, 11 public entities, 20 child-serving organizations, two funders and four } \\
\text { institutions of higher learning. }\end{array}$ & & \\
\hline
\end{tabular}

An online consent script informed each participant that anonymous responses would be used in group format for technical reports and publications; consent required acknowledgement (I Agree) before entry to the training surveys. Pre-intervention data were collected during registration. Following the EBP training, participants answered post-intervention questions like the pre questions. We developed retrospective only (post-then-pre) post instruments to reduce response-shift bias. Colosi and Dunifon (2006) mentioned threats to validity with the retrospective method as,

- Recall: inability to accurately recall past attitudes and behaviors.

- Social desirability: need to report improvement to fit expectations or inflate perceived improvement for most important items.

- Effort justification: report improvement (subconsciously) to justify time and energy invested in program attendance.

- Cognitive dissonance: report improvement even if unrealized, to meet self-expectations of change.

Not all participants completed all intervention assessments; therefore, only paired data are reported herein.

Perceptions and knowledge of EBP interventions were collected with instruments based on Kirkpatrick's second level of evaluation (i.e., learning); all instruments used Likert-type, 5-point scales (i.e., 1 = strongly disagree, $5=$ strongly agree; $1=$ low, $5=$ high; $1=$ very uncomfortable, $5=$ very comfortable; $1=$ poor, $5=$ excellent; 1 = never, 5 = always). Concerning perceptions, the $\mathrm{CMH}$ intervention included five pre/post items rated on a 5-point scale (strongly disagree to strongly agree). Cronbach's (1951) alphas were .92 (pre) and .94 (post); both were highly reliable. Five retrospective-only items were rated with 5-point scales (poor to excellent; very uncomfortable to very comfortable). Cronbach's (1951) alphas were .80 (before) and .79 (after), also deemed reliable. The TIC intervention used retrospective only items with 5-point scales (low to high). Cronbach's (1951) alphas were .89 (before) and .92 (after); deemed highly reliable. The YSP intervention included eight items (retrospective only) with a 5-point scale (poor to excellent). 
Cronbach's (1951) alphas were .93 (before and after); deemed highly reliable. T102 intervention included eight items for knowledge and comfort levels (retrospective only) on a 5-point scale (poor to excellent). Cronbach's (1951) alphas were .95 (before) and .97 (after): deemed highly reliable. The SCM intervention had three pre/post and ten retrospective items for knowledge and comfort on 5-point scales (never to always; poor to excellent). Cronbach's (1951) alphas were .74 (pre) and .97 (post) and .84 (before) and .95 (after) in retrospective only; all were highly reliable.

Knowledge was tested with questions from the EBP curricula. Twelve pre/post questions in T102 and 11 pre/post SCM knowledge questions were posed as single (4-item multiple-choice) or multiple response (check all correct) items. Testing effect threats were minimized by randomizing question and response order (Campbell \& Stanley 1963). Participants' responses were dichotomously coded ( $0=$ incorrect, $1=$ correct). Kuder-Richardson 20 (KR20) reliability coefficients was used because the KR20 appropriately determines internal consistency of measurements with dichotomous data (Fraenkel et al., 2019). KR20 for T102 was .71 (pre) and .64 (post); SCM yielded reliability .47 (pre) and .58 (post). Reliability was attributed to heterogeneity of items and item discrimination (Frisbie, 1988), and limited number of questions. Results should not be generalized beyond the sample when KR20 scores are less than .60 (Ursachi et al., 2015). Knowledge results represent only those in MHAGH's EBP trainings.

Participants demographic characteristics were recorded during registration. All valid paired data were assigned unique numbers and personal information was removed before analyses. Descriptive and inferential statistics described the data. Alpha was .05 a-priori to determine if significant differences existed in pre/post perceptions or knowledge. Non-parametric tests (e.g., Friedman, McNemar) were used because normality of data from non-random samples could not assumed.

Multiple purposive (non-probability) samples were drawn from EBP intervention trainees. Due to space limitations, only their primary demographics are in Table 2. Each intervention included more than 400 participants. We calculated power using G*Power 3.1.9.7 (Faul et al., 2007); sensitivity analysis indicated a sample of 400 was large enough to detect within-subject interactions (i.e., post hoc matched pairs; a $=.05)$ as small as $d=.2$ with $98 \%$ power. Participants were characterized as female ( $62 \%)$, white $(\sim 31 \%)$, teachers $(\sim 63 \%)$, who were $36-45$ years old $(\sim 20 \%)$ (Table 2$)$. They were 41 years $(S D=10.90)$ old. 
Table 2

Participants' Characteristics from EBP Intervention Trainings (2019-2020).

\begin{tabular}{|c|c|c|c|c|c|c|c|c|c|c|}
\hline \multirow[b]{2}{*}{ Variables* } & \multicolumn{2}{|c|}{$\begin{array}{l}\text { CMH } \\
(N=1,066)\end{array}$} & \multicolumn{2}{|c|}{$\begin{array}{l}\text { TIC } \\
(N=2,133)\end{array}$} & \multicolumn{2}{|c|}{$\begin{array}{l}\text { YSP } \\
(N=1,673)\end{array}$} & \multicolumn{2}{|c|}{$\begin{array}{l}\text { T102 } \\
(N=428)\end{array}$} & \multicolumn{2}{|c|}{$\begin{array}{l}\text { SCM } \\
(N=401)\end{array}$} \\
\hline & $n$ & $\%$ & $n$ & $\%$ & $n$ & $\%$ & $n$ & $\%$ & $n$ & $\%$ \\
\hline \multicolumn{11}{|l|}{ Sex ${ }^{a}$} \\
\hline Female & 618 & 58.0 & 754 & 35.3 & 747 & 44.7 & 379 & 88.6 & 340 & 84.8 \\
\hline Male & 179 & 16.8 & 202 & 9.5 & 183 & 10.9 & 35 & 8.2 & 42 & 10.5 \\
\hline \multicolumn{11}{|l|}{ Race $^{b}$} \\
\hline White & 430 & 40.3 & 527 & 24.7 & 545 & 32.6 & 213 & 49.8 & 22 & 5.5 \\
\hline Hispanic & 163 & 15.3 & 175 & 8.2 & 201 & 12.0 & 92 & 21.5 & 86 & 21.4 \\
\hline Black & 131 & 12.3 & 139 & 6.5 & 107 & 6.4 & 61 & 14.3 & 96 & 23.9 \\
\hline \multicolumn{11}{|l|}{ Age } \\
\hline $26-35$ & 254 & 23.8 & 279 & 13.1 & 283 & 16.9 & 101 & 23.6 & 99 & 24.7 \\
\hline $36-45$ & 244 & 22.9 & 262 & 12.3 & 274 & 16.4 & 154 & 36.0 & 116 & 28.9 \\
\hline $46-55$ & 162 & 15.2 & 208 & 9.8 & 212 & 12.7 & 92 & 21.5 & 76 & 19.0 \\
\hline \multicolumn{11}{|l|}{ Profession } \\
\hline Teacher & 792 & 74.3 & 1360 & 63.8 & 1,092 & 65.3 & 215 & 50.2 & 239 & 59.6 \\
\hline Paraprofessional & 63 & 5.9 & 178 & 8.3 & 113 & 6.8 & 36 & 8.4 & 49 & 12.2 \\
\hline Counselor & 7 & .7 & 115 & 5.4 & 109 & 6.5 & 109 & 25.5 & 47 & 11.7 \\
\hline Other Staff c & 57 & 5.3 & 106 & 5.0 & 116 & 6.9 & 44 & 10.3 & 37 & 9.2 \\
\hline
\end{tabular}

The professional development activities and data reported herein are not considered research involving human subjects as defined by DHHS and/or FDA regulations. This study was exempt by an Institutional Review Board at [STATE UNIVERSITY]. 
Objective one was to assess and determine if significant changes occurred in participants' perceptions of the EBP intervention. Perception analyses for the $\mathrm{CMH}$ intervention are in Table 3. Friedman tests revealed significant changes in respondents' $(n=1,065)$ perceptions of mental illnesses involving changes in health. Perceptions changed from agree $\left(M d_{\text {pre }}=4.0\right)$ to strongly agree $\left(M d_{\text {post }}=5.0\right)$ after the $\mathrm{CMH}$ intervention. In the retrospective only assessment, respondents' comfort levels significantly increased from good $\left(M d_{\text {before }}=3.0\right)$ to very good $\left(M d_{\text {after }}=4.0\right)$ for understanding whether a student may be developing a mental health challenge. Comfort levels significantly increased from comfortable $\left(M d_{\text {before }}=4.0\right)$ to very comfortable $\left(M d_{\text {after }}=5.0\right)$ for approaching the student, school support staff, or administrators to discuss students' mental health issues. Effect size magnitude was interpreted using $W_{\text {Kendall }}$ based on Cohen's (1992) benchmarks. Negligible $(\leq 0.1)$, moderate $(0.3)$ and large $(\geq 0.5)$ effects were found. 
Table 3

Significance and Effect Sizes for Changes in CMH Perceptions, $2019-2020(n=1,063)$.

\section{Medians}

Statements ${ }^{\text {a }}$ (Pre/Post)

Pre Post $d f \quad \chi^{2 \mathrm{~d}}$

W

e

Mental illnesses are health conditions involving significant changes in... thinking.

$\begin{array}{lllll}4 & 5 & 1 & 77.13^{*} & .07\end{array}$

...emotions.

4

...behavior.

4

$\begin{array}{llll}5 & 1 & 44.06^{*} \quad .04\end{array}$

...a combination (thinking, emotions, and behavior).

5

Early adverse life experiences can be a strong risk factor for developing mental illness.

Statements (Retrospective post only)

Before After

Understanding whether a student may be developing a

mental health challenge. ${ }^{b}$

34

4

1

$684.06 * \quad .64$

Comfort level when approaching... ${ }^{c}$

a student you are concerned about.

parent or guardian of a student.

school support staff with your student concerns.

school administrators with your student concerns.

$\begin{array}{lllll}4 & 5 & 1 & 444.57^{*} & .42 \\ 4 & 4 & 1 & 513.87 * & .48 \\ 4 & 5 & 1 & 347.50 * & .33 \\ 4 & 5 & 1 & 336.75^{\star} & .32\end{array}$

Note. ${ }^{a}$ Scale: strongly disagree (1), disagree (2), uncertain (3), agree (4) and strongly agree (5). ${ }^{b}$ Scale: poor (1), fair (2), good (3), very good (4) and excellent (5). ${ }^{c}$ Scale: very uncomfortable (1), uncomfortable (2), neither comfortable or uncomfortable (3), comfortable (4) and very comfortable (5). ${ }^{d}$ Friedman test. ${ }^{e}$ Kendall's Coefficient of Concordance uses Cohen's explanations of effect sizes, including 0.1 (small), 0.3 (moderate) and $\geq 0.5$ (large).

$* p<.001$.

$\mathrm{n}$

Primary perception analyses for the TIC intervention are in Table 4. Friedman tests revealed significant increases in respondents' $(n=1,215)$ median rankings for self-perceived understanding of the influence of trauma on learning, increasing from average $\left(M d_{\text {before }}=3.0\right)$ to high $\left(M d_{\text {after }}=5.0\right)$; and knowledge of trauma and/or grief informed classrooms increased from average $\left(M d_{\text {before }}=3.0\right)$ to above average $\left(M d_{\mathrm{after}}=4.0\right)$. Large $(\geq 0.5)$ effect sizes were noted. 
Table 4

Significance and Effect Sizes for Changes in TIC Perceptions, 2019-2020 $(n=1,215)$.

\begin{tabular}{|c|c|c|c|c|c|}
\hline \multirow[b]{2}{*}{ Statements ${ }^{a}$ (Retrospective post only) } & \multicolumn{5}{|c|}{ Medians } \\
\hline & Before & After & $d f$ & $\chi^{2 b}$ & $W^{c}$ \\
\hline Understanding of the influence of trauma on learning. & 3 & 5 & 1 & $812.17 *$ & .67 \\
\hline Knowledge of trauma informed classroom. & 3 & 4 & 1 & $886.11^{\star}$ & .73 \\
\hline Knowledge of grief informed classroom. & 3 & 4 & 1 & $845.87^{\star}$ & .70 \\
\hline \multicolumn{6}{|c|}{$\begin{array}{l}\text { Note. }{ }^{\text {a }} \text { Scale: low (1), below average (2), average (3), above average (4) and high (5). }{ }^{\mathrm{b}} \text { Friedman test. } \\
{ }^{\mathrm{c}} \text { Kendall's Coefficient of Concordance uses Cohen's effect size; } \geq 0.5 \text { (large). } \\
{ }^{\star} p<.001 .\end{array}$} \\
\hline
\end{tabular}

Primary perception analyses for the YSP intervention are in Table 5. Friedman tests revealed significant changes in respondents' $(n=1,160)$ self-perceived knowledge of the actions to take when a student is atrisk of suicide and the signs and symptoms of suicide risk in students. Both items changed from good $\left(M d_{\text {before }}=3.0\right)$ to very good $\left(M d_{\text {after }}=4.0\right)$ after the YSP intervention. Confidence in approaching a student, helping a student, asking a student about suicide, and approaching school counselors, administrators, or parents/guardians about students at risk of suicide changed from good $\left(M d_{\text {before }}=\right.$ $3.0)$ to very good $\left(M d_{\text {after }}=4.0\right)$. Large $(\geq 0.5)$ effect sizes were noted. 
Table 5

Significance and Effect Sizes for Changes in YSP Perceptions, 2019-2020 $(n=1,160)$.

\begin{tabular}{|c|c|c|c|c|c|}
\hline \multirow[b]{2}{*}{ Statements ${ }^{a}$ (Retrospective post only) } & \multicolumn{5}{|c|}{ Medians } \\
\hline & Before & After & $d f$ & $\chi^{2 \mathrm{~b}}$ & $W^{c}$ \\
\hline \multicolumn{6}{|l|}{ Knowledge of... } \\
\hline the actions to take if a student is at-risk of suicide. & 3 & 4 & 1 & $858.54 *$ & .74 \\
\hline signs and symptoms of suicide risk in students. & 3 & 4 & 1 & $853.04 *$ & .74 \\
\hline \multicolumn{6}{|l|}{ Confidence in... } \\
\hline approaching a student at risk of suicide. & 3 & 4 & 1 & $832.04 *$ & .72 \\
\hline helping a student at risk of suicide. & 3 & 4 & 1 & $834.08^{\star}$ & .72 \\
\hline asking a student about suicide. & 3 & 4 & 1 & $848.07 *$ & .73 \\
\hline approaching a school counselor about a student at risk. & 3 & 4 & 1 & $673.14^{\star}$ & .58 \\
\hline approaching an administrator about a student at risk. & 3 & 4 & 1 & $654.15^{\star}$ & .56 \\
\hline approaching a parent/guardian about a student at risk. & 3 & 4 & 1 & $799.02 *$ & .69 \\
\hline \multicolumn{6}{|c|}{$\begin{array}{l}\text { Note. }{ }^{\text {a }} \text { Scale: poor ( } 1 \text { ), to fair (2), good (3), very good (4) and excellent (5). }{ }^{\mathrm{b}} \text { Friedman test. }{ }^{\mathrm{c}} \text { Kendall's } \\
\text { Coefficient of Concordance uses Cohen's effect size; } \geq 0.5 \text { (large). }\end{array}$} \\
\hline
\end{tabular}

Perception analyses for the T102 intervention are in Table 6. Friedman tests revealed significant increases in respondents' $(n=428)$ median rankings for self-perceived knowledge of the cultural considerations of trauma, historical trauma, racial trauma, implicit bias, and equity; all increased from good $\left(M d_{\text {before }}=3.0\right)$ to very good $\left(M d_{\text {after }}=4.0\right)$ after the T102 intervention training in 2020. Comfort levels for responding to students with trauma, historical trauma, and/or racial trauma increased significantly from good to very good. Moderate $(0.3)$ to large $(\geq 0.5)$ effect sizes were noted. 
Table 6

Significance and Effect Sizes for Changes in T102 Perceptions, $2020(n=428)$.

\begin{tabular}{|c|c|c|c|c|c|}
\hline & Medians & & & & \\
\hline Statements ${ }^{a}$ (Retrospective post Only) & Before & After & $d f$ & $\chi 2^{b}$ & $W^{\mathrm{c}}$ \\
\hline \multicolumn{6}{|l|}{ Knowledge of... } \\
\hline the cultural considerations of trauma. & 3 & 4 & 1 & $227.50 *$ & .53 \\
\hline historical trauma. & 3 & 4 & 1 & $251.13^{*}$ & .59 \\
\hline racial trauma. & 3 & 4 & 1 & $211.59 *$ & .50 \\
\hline implicit bias. & 3 & 4 & 1 & $234.47 *$ & .55 \\
\hline equity. & 3 & 4 & 1 & 198.36* & .47 \\
\hline \multicolumn{6}{|c|}{ Comfort level for responding to students with... } \\
\hline trauma. & 3 & 4 & 1 & $163.76^{*}$ & .38 \\
\hline historical trauma. & 3 & 4 & 1 & 195.39* & .46 \\
\hline racial trauma. & 3 & 4 & 1 & $207.62^{\star}$ & .49 \\
\hline \multicolumn{6}{|c|}{$\begin{array}{l}\text { Note. }{ }^{\text {a }} \text { Scale: poor ( } 1 \text { ), fair (2), good (3), very good (4) and excellent (5). }{ }^{\text {b }} \text { Friedman test. }{ }^{c} \text { Kendall's } \\
\text { Coefficient of Concordance uses Cohen's effect sizes from } 0.3 \text { (moderate) to } \geq 0.5 \text { (large). }\end{array}$} \\
\hline
\end{tabular}

Perception analyses for the SCM intervention are in Table 7. Friedman tests revealed significant differences $\left(\chi^{2}(1)=127.52, p=0.001\right)$ in respondents' $(n=401)$ median rankings for engaging in selfcare, although it was ranked as often $(M d=4.0)$ in pre/post-intervention. Moderate (0.3) effects were found in respondents' perceived engagement in mindfulness practice and practicing mindfulness with students. Both items increased from sometimes $\left(M d_{\text {pre }}=3.0\right)$ to often $\left(M d_{\text {post }}=4.0\right)$. Respondents' selfperceived knowledge and understanding increased significantly $(p<.001)$ from good to very good for incorporating selfcare into daily routines, use of SMART goals in self-care, research that supports mindfulness, how to be attentive and aware and knowledge of practices to help oneself be present and attentive increased after the SCM intervention. Self-perceived knowledge of the impact stress has on health and how self-care can improve stress were rated as very good $(M d=4.0)$, before and after training. Knowledge and understanding of the role of the vagus nerve increased significantly $\left(\chi^{2}(1)=200.84, p=\right.$ 0.001) from fair to good after the SCM intervention. 
Table 7

Significance and Effect Sizes for Changes in SCM Perceptions, $2020(n=401)$.

\section{Medians}

\begin{tabular}{|c|c|c|c|c|c|}
\hline Statements ${ }^{\text {a }}$ (Pre/Post) & Pre & Post & $d f$ & $\chi 2^{c}$ & $W^{\mathrm{d}}$ \\
\hline \multicolumn{6}{|l|}{ How often do you... } \\
\hline engage in self-care? & 4 & 4 & 1 & $127.52^{\star}$ & .33 \\
\hline engage in mindfulness practice? & 3 & 4 & 1 & $179.86^{\star}$ & .45 \\
\hline practice mindfulness with students? & 3 & 4 & 1 & $167.54^{\star}$ & .42 \\
\hline Statements ${ }^{b}$ (Retrospective post only) & Before & After & & & \\
\hline \multicolumn{6}{|l|}{ Knowledge and understanding of... } \\
\hline how to incorporate selfcare into daily life. & 3 & 4 & 1 & $189.24^{\star}$ & .47 \\
\hline use SMART goals in self-care. & 3 & 4 & 1 & $216.29 *$ & .54 \\
\hline the impact stress has on health. & 4 & 4 & 1 & $131.96^{\star}$ & .33 \\
\hline how self-care can improve stress. & 4 & 4 & 1 & $142.10 *$ & .36 \\
\hline research that supports mindfulness. & 3 & 4 & 1 & $180.84^{\star}$ & .45 \\
\hline the role of the vagus nerve. & 2 & 3 & 1 & $200.84^{\star}$ & .50 \\
\hline how to pay attention. & 3 & 4 & 1 & $158.33^{\star}$ & .40 \\
\hline how to increase my awareness. & 3 & 4 & 1 & $183.21^{\star}$ & .46 \\
\hline practices to help me be present. & 3 & 4 & 1 & $195.41^{\star}$ & .49 \\
\hline practices to help me pay attention. & 4 & 4 & 1 & $186.12^{\star}$ & .47 \\
\hline \multicolumn{6}{|c|}{ 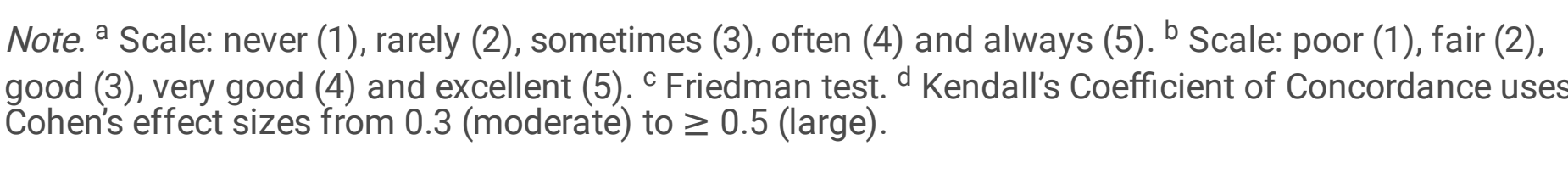 } \\
\hline$\star p<.001$ & & & & & \\
\hline
\end{tabular}

Objective two was to assess and determine if significant changes occurred in participants' knowledge of selected Emotional Backpack Project topics. Knowledge analyses for the T102 intervention $(n=428)$ are in Table 8. An exact McNemar's test revealed significant increases in proportions of correct responses for trauma informed schools are consistent, predictable, positive $(p=.001)$ and safe $(p=.01)$. Knowledge gains ranged from $\sim 4 \%$ to $\sim 29 \%$. Significantly more correct responses were chosen for trauma informed educators foster cultural awareness and promote equity $(p=.001)$ after training. Knowledge gains ranged from $\sim 5 \%$ to $~ 7 \%$. 
Table 8

Frequencies and Chi-Square Results for Correct T102 Knowledge, $2020(n=428)$.

\begin{tabular}{|c|c|c|c|c|c|c|}
\hline & Pre & & Post & & & \\
\hline Questions & $n$ & $\%$ & $n$ & $\%$ & $\chi^{2 \mathrm{a}}$ & $p$ \\
\hline \multicolumn{7}{|l|}{ Trauma informed schools are: } \\
\hline consistent & 375 & 87.6 & 418 & 97.7 & $36.00 *$ & .00 \\
\hline inflexible ${ }^{b}$ & 411 & 96.0 & 417 & 97.4 & 1.79 & $.18^{c}$ \\
\hline predictable & 205 & 47.9 & 328 & 76.6 & $104.08^{*}$ & .00 \\
\hline positive & 363 & 84.8 & 410 & 95.8 & $38.47^{\star}$ & .00 \\
\hline unstructured $^{\mathrm{b}}$ & 417 & 97.4 & 423 & 98.8 & 2.50 & $.11^{\mathrm{c}}$ \\
\hline safe & 386 & 90.2 & 405 & 94.6 & $6.89 *$ & .01 \\
\hline \multicolumn{7}{|l|}{ Trauma informed educators: } \\
\hline provide therapy to students ${ }^{b}$ & 318 & 74.3 & 327 & 76.4 & 1.26 & $.26^{c}$ \\
\hline show empathy & 414 & 96.7 & 419 & 97.9 & 0.84 & $.36^{\mathrm{c}}$ \\
\hline do not set boundaries ${ }^{b}$ & 396 & 92.5 & 399 & 93.2 & 0.19 & $.66^{\mathrm{c}}$ \\
\hline foster cultural awareness & 379 & 88.6 & 402 & 93.9 & $10.30 *$ & .00 \\
\hline promote equity & 382 & 89.3 & 413 & 96.5 & $20.00 *$ & .00 \\
\hline ask students about the details of their trauma ${ }^{b}$ & 358 & 83.6 & 355 & 82.9 & 0.07 & $.79^{c}$ \\
\hline \multicolumn{7}{|c|}{ Note. ${ }^{a}$ McNemar test. ${ }^{b}$ Incorrect. ${ }^{c}$ Binomial distribution. } \\
\hline
\end{tabular}

Knowledge analyses for the SCM intervention $(n=401)$ are in Table 9. An exact McNemar's test showed a significant $(p=.001)$ increase (8.5\%) of correct responses for the post-intervention question, scholarly research finds that mindfulness practice increases attention. Significantly $(p=.001)$ more correct responses were selected for post-intervention questions, "Diaphragmatic breathing activates [the vagus nerve]" (12\% increase), and "What does the S in SMART goals mean? [Specific - a goal must be focused]" ( 14\% increase). 
Table 9

Frequencies and Chi-Square Results for Correct SCM Knowledge, $2020(n=401)$.

\begin{tabular}{|c|c|c|c|c|c|c|}
\hline & Pre & & Post & & & \\
\hline Questions & $n$ & $\%$ & $n$ & $\%$ & $\chi^{2 \mathrm{a}}$ & $p$ \\
\hline \multicolumn{7}{|l|}{ Research shows mindfulness practice: } \\
\hline decreases stress and anxiety & 380 & 94.8 & 367 & 91.5 & 3.20 & .07 \\
\hline increases attention & 321 & 80.0 & 355 & 88.5 & $13.28^{*}$ & .00 \\
\hline increases IQ & 189 & 47.1 & 183 & 45.6 & 0.25 & .62 \\
\hline improves interpersonal relationships & 348 & 86.8 & 343 & 85.5 & 0.23 & .64 \\
\hline $\begin{array}{l}\text { Mindfulness helps us calm the limbic system so we } \\
\text { can connect with our [higher-level functions]. }\end{array}$ & 154 & 38.4 & 157 & 39.2 & 0.03 & .86 \\
\hline $\begin{array}{l}\text { The proper technique for a deep breath is to [extend] } \\
\text { your stomach on inhale and [contract] it on exhale. }\end{array}$ & 184 & 45.9 & 200 & 49.9 & 2.30 & .13 \\
\hline Diaphragmatic breathing activates [the vagus nerve]. & 199 & 49.6 & 247 & 61.6 & $16.74^{*}$ & .00 \\
\hline $\begin{array}{l}\text { What does the S in SMART goals mean? [Specific - a } \\
\text { goal must be focused]. }\end{array}$ & 279 & 69.6 & 334 & 83.3 & $28.87^{*}$ & .00 \\
\hline $\begin{array}{l}\text { Incorporating consistent mindfulness practice into } \\
\text { your curriculum is a great way to promote [social] and } \\
\text { emotional learning in your classroom. }\end{array}$ & 182 & 45.4 & 189 & 47.1 & 0.40 & .53 \\
\hline $\begin{array}{l}\text { Mindfulness draws on an explicit value system that } \\
\text { emphasizes wholesome attitudes including all the } \\
\text { following EXCEPT [formality]. }\end{array}$ & 311 & 77.5 & 298 & 74.3 & 1.43 & .23 \\
\hline $\begin{array}{l}\text { Youth are prone to making unwise decisions when an } \\
\text { overstimulated limbic system causes decreased } \\
\text { thought processes in the [prefrontal cortex]. }\end{array}$ & 207 & 51.6 & 212 & 52.9 & 0.11 & .74 \\
\hline \multicolumn{6}{|l|}{ Note. ${ }^{a}$ McNemar test. } & \\
\hline
\end{tabular}

\section{Discussion}

The EBP intervention produced significant improvements in school personnel mental health literacy and knowledge of students' behavioral and mental health issues. EBP training changed participants' attitudes about students' mental health issues, even for school personnel with positive perceptions at baseline. MHAGH's trainings were "successful in meeting educators' needs as well as enhancing educators' confidence in effectively addressing youth mental health needs in schools" (Wei \& Kutcher, 2014, p. 221). Our primary findings support the notion that professional development for school personnel helping 
students cope with behavioral and mental health issues can produce desired learner outcomes in selected Texas schools. Kirkpatrick and Kirkpatrick's (2006) program evaluation framework for assessing learner outcomes in training programs is supported.

We affirmed previous work (Jorm et al., 2010) about educators' increased knowledge and changed beliefs about students' mental health issues and increased their confidence in addressing such issues. Changes in beliefs about students' mental health may lead to broader understanding of student behavior and academic achievement. We found significant increases in educators' confidence to help students at risk of suicide, which is encouraging for the $12 \%$ of Texan teenagers who said they attempted suicide in 2017 (“Texas 2017 Results", 2018). EBP intervention training could provide earlier detection of students with suicidal ideation, thus promoting help-seeking behaviors from trained educators.

Unfortunately, students' mental health issues were exacerbated during the novel Coronavirus 2019 (COVID-19) pandemic. Hill et al. (2021) found rates of suicide ideation and attempts were higher in 2020 compared to 2019 , for youth aged 11 to 21 in a major Texas city. The onset of COVID-19 led to high unemployment, diminished income, and increased food and housing assistance needs (Sharma et al., 2020). These challenges compound trauma and toxic stress, leaving youth feeling unsafe, overwhelmed, and helpless. Educators who are comfortable addressing youth are crucial frontline responders for students' mental health issues. Texan youth will continue experiencing life and school stressors that affect their behavioral and mental health. We advocate for increased school personnel training to build capacity for helping students cope with behavioral and mental issues in Texas.

Consistent with previous research (Eustache et al., 2017; Jorm et al., 2010; Kutcher et al., 2015; Wei \& Kutcher, 2014), participants' self-perceived knowledge of students' behavioral and mental health issues increased after training. Self-care practices, including mindfulness and knowledge about self-care, are important components to reduce secondary traumatic stress (Lawson et al., 2019). Post-intervention results showed participants felt very good (confidence) about approaching school counselors, administrators, or students to discuss at-risk youth behaviors. These positive trends can help reduce educators' secondary traumatic stress by encouraging discussion about students at risk and fostering self-care practices needed after traumatic experiences. These trends also lend themselves to earlier interventions and better outcomes.

Educators' responses to students can be harmful or healing and may depend on the teacher's mental and emotional state. We encourage educators to have short- and long-term self-care plans to remain clear minded when responding to disruptive students. Lawson et al. (2019) noted that educators who interacted with traumatized students were themselves vulnerable to secondary traumatic stress. Dye et al. (2020) found that mindfulness training significantly helped counselors' relaxation strategies. We advocate for schools integrating mindfulness practices into daily routines to support staff's mental health and wellness.

School-based mental health professionals' confidence or comfort levels for approaching students to discuss mental health needs increased after training. School-based mental health professionals and 
administrators are underutilized resources in promoting positive mental health in schools (Atkins et al., 2010; Barrett et al., 2013; Jensen et al., 2011). Our interventions were attended by non-teachers, sometimes as much as $33 \%$ were school personnel from outside the classroom; increasing those participants' confidence and comfort is needed when approaching students to discuss mental health needs. If more school personnel were confident and/or comfortable with approaching students, they might find support systems sooner, knowing that youth ( $<18$ years) do not seek formal health support (Kelly et al., 2011 cited in Anderson et al., 2019).

Participants were comfortable in approaching parents or guardians of students they were concerned about following the $\mathrm{CMH}$ intervention training and very comfortable approaching students or school support staff and administrators for the same reasons. We see a common, but potentially harmful gap in addressing students' behavioral and mental health issues through a whole-community approach. Do teachers not discuss concerns about at-risk students with parents or guardians for fear of crossing a caregiver boundary, despite being in the student's best interest? Hatton et al. (2017) reported secondary school teachers feared intervening with potentially suicidal students, while Ohrt et al. (2020) noted teachers' training programs on mental health were missing communication skills building to interact with students with mental health issues. Our findings extend the lacking communication skills' premise to include parents and/or guardians.

We believe less comfort in approaching parents or guardians is because of lacking communication skills or confidence as the students' behavioral and mental health advocate. It could be the result of unfamiliarity in discussing such matters with diverse families. Future training can build educators' confidence and comfort in approaching parents or guardians by practicing improved communication skills. Although time-consuming, adequate training includes practicing communications, messaging, and listening skills. Role-play simulation, debriefing, and lessons learned reinforces communication strategies and increases teachers' confidence in mental health training.

A limitation was the lack of a control group to compare the impact of participation vs. non-participation in MHAGH's intervention trainings. Future studies should use experimental or quasi-experimental designs to measure the impact of professional development activities more effectively. Limitations exist in using retrospective post-intervention only evaluations. Retrospective assessment might have introduced threats that interfered with measuring knowledge and/or confidence (Colosi \& Dunifon, 2006). Improved program evaluation design will reduce or control most threats to internal validity.

Mental health training helped educators and school personnel develop knowledge and confidence in addressing students' behavioral and mental health issues. Increased knowledge of mental illnesses can affect action because informed educators can identify and refer students to mental health services. We recommend mental health training that increases knowledge about students' mental health needs be conducted more frequently than once annually. Training to build educators' confidence to help students with mental health issues and communication skills with primary caregivers is needed. It may help to study the implications of including cultural relevance in mental health training curricula to increase 
confidence. Confidence-boosting interventions can be designed for specific audiences (i.e., students, parents, or educators) for use when communicating with at-risk students. Online intervention materials about students' behavioral and mental health needs could help educators retain knowledge after in person or online training. Role-play simulation will improve educators' confidence and communication skills for interacting with others to address students' behavioral and mental health issues.

\section{Declarations}

Disclosure of potential conflicts of interest: The authors have no competing interests to declare that are relevant to the content of this article. This work was partially supported by the Center for School Behavioral Health at Mental Health America of Greater Houston though consulting fees to conduct program evaluations.

Research involving Human Participants: All experimental protocols were approved by the Texas A\&M University Institutional Review Board (\#IRB2019-1309). All methods were carried out in accordance with relevant guidelines and regulations. The Texas A\&M University Institutional Review Board determined that the proposed activity (i.e., program evaluations) was not research involving human subjects as defined by DHHS and FDA regulations.

Informed consent: Informed consent was obtained from all subjects and/or their legal guardian(s) by acknowledging agreement with an online consent script before accessing online surveys. The Texas A\&M University Institutional Review Board waived the process to document consent because this study did not involve more than minimal risk.

Acknowledgement: We thank all teachers, school personnel, and intervention trainers who participated in professional development workshops and those who provided data for this report. The authors thank [CONTRIBUTORS] for their assistance in writing this document.

Data availability: Datasets generated and analyzed during this study are available from the corresponding author on reasonable request.

Ethics declaration: This was an observational study. All experimental protocols were approved by the [UNIVERSITY] Institutional Review Board (\#IRB2019-1309). All methods were carried out in accordance with relevant guidelines and regulations. The [UNIVERSITY] Institutional Review Board determined that the proposed activity (i.e., program evaluations) was not research involving human subjects as defined by DHHS and FDA regulations.

Consent to participate: Informed consent was obtained from all subjects and/or their legal guardian(s) by acknowledging agreement with an online consent script before accessing online surveys.

The [UNIVERSITY] Institutional Review Board waived the process to document consent because this study did not involve more than minimal risk.

Declarations: The authors declare no competing interests. 


\section{References}

1. Anderson, M., Werner-Seidler, A., King, C., Gayed, A., Harvey, S. B., \& O'Dea, B. (2019). Mental health training programs for secondary school teachers: A systematic review. School Mental Health 11, 489-508. https://doi.org/10.1007/s12310-018-9291-2

2. Atkins, M. S., Hoagwood, K. E., Kutash, K., \& Seidman, E. (2010). Toward the integration of education and mental health in schools. Administration and Policy in Mental Health and Mental Health Services Research, 37(1), 40-47. https://doi.org/10.1007/s10488-010-0299-7

3. Barrett, S., Eber, L., \& Weist, M. (2013). Advancing education effectiveness: Interconnecting school mental health and school-wide positive behavior support. OSEP Center for Positive Behavioral Interventions and Supports.

4. Buchele, M. (2018, May 23). Here are 22 ideas Gov. Abbott shared for stopping school shootings. KUT 90.5, Austin's NPR Station. https://www.kut.org/post/here-are-22-ideas-gov-abbott-sharedstopping-school-shootings

5. Campbell, D. T., \& Stanley, J. C. (1963). Experimental and quasi-experimental designs for research on teaching. In N. L. Gage (Ed.), Handbook of research on teaching. Rand McNally, 171-246.

6. Carr, W., Wei, Y., Kutcher, S., \& Heffernan, A. (2017). Preparing for the classroom: Mental health knowledge improvement, stigma reduction and enhanced help-seeking efficacy in Canadian preservice teachers. Canadian Journal of School Psychology, 33(4), 314-326. https://doi.org/10.1177/0829573516688596

7. Centers for Disease Control and Prevention. (2018). Multiple cause of death 1999-2018 on CDC WONDER online database, released in 2020 [dataset]. Multiple Cause of Death 1999-2018. https://wonder.cdc.gov/controller/datarequest/D77

8. Cohen, J. (1992). A power primer. Psychological Bulletin, 112(1), 155-159. doi:10.1037//00332909.112.1.155

9. Colosi, L., \& Dunifon, R. (2006). What's the difference? 'Post then pre' \& 'Pre then post.'Cornell Cooperative Extension; 29.

10. Dye, L., Burke, M. G., \& Wolf, C. (2020). Teaching mindfulness for the self-care and well-being of counselors-in-training. Journal of Creativity in Mental Health, 15(2), 140-153.

https://doi.org/10.1080/15401383.2019.1642171

11. Eustache, E., Gerbasi, M., Smith Fawzi, M., Fils-Aimé, J., Severe, J., Raviola, G., Legha, S., Darghouth, S., Grelotti, D. J., Thérosmé, T., Pierre, E. L., Affricot, E., Alcindor, Y., Stack, M. B., \& Becker, A. (2017). Mental health training for secondary school teachers in Haiti: A mixed methods, prospective, formative research study of feasibility, acceptability, and effectiveness in knowledge acquisition. Global Mental Health, 4, E4. https://doi.org/10.1017/gmh.2016.29

12. Faul, F., Erdfelder, E., Lang, A. G., \& Buchner, A. (2007). G*Power 3: A flexible statistical power analysis program for the social., behavioral and biomedical sciences. Behavior Research Methods, 39(2), 175-191. 
13. Fraenkel, J. R., Wallen, N. E., \& Hyun, H. (2019). How to design and evaluate research in education (10th ed.). McGraw-Hill Professional Publishing.

14. Frisbie, D. A. (1988). Reliability of scores from teacher-made tests. Educational measurement: Issues and Practice, 7(1), 25-35. doi:10.1111/j.1745-3992.1988.tb00422.x

15. Frye, A. W., \& Hemmer, P. A. (2012). Program evaluation models and related theories: AMEE guide no. 67. Medical Teacher, 34(5), e288-e299. https://doi.org/10.3109/0142159X.2012.668637

16. Hatton, V., Heath, M. A., Gibb, G. S., Coyne, S., Hudnall, G., \& Bledsoe, C. (2017). Secondary teachers' perceptions of their role in suicide prevention and intervention. School Mental Health, 9(1), 97-116. https://doi.org/10.1007/s12310-015-9173-9

17. Hill, R. M., Rufino, K., Kurian, S., Saxena, J., Saxena, K., \& Williams, L. (2021). Suicide ideation and attempts in a pediatric emergency department before and during COVID-19. Pediatrics, 147 (3), e2020029280. https://doi.org/10.1542/peds.2020-029280

18. Jensen, P. S., Goldman, E., Offord, D., Costello, E. J., Friedman, R., Huff, B., Crowe, M., Amsel, L., Bennett, K., Bird, H., Conger, R., Fisher, P., Hoagwood, K., Kessler, R., C., \& Roberts, R. (2011). Overlooked and underserved: 'Action signs' for identifying children with unmet mental health needs. Pediatrics, 128(5), 970-979. https://pediatrics.aappublications.org/content/128/5/970

19. Jorm, A. F., Kitchener, B. A., Sawyer, M. G., Scales, H., \& Cvetkovski, S. (2010). Mental health first aid training for high school teachers: A cluster randomized trial. BMC Psychiatry, 10(1), 51. https://doi.org/10.1186/1471-244X-10-51

20. Kern, L., Mathur, S. R., Albrecht, S. F., Poland, S., Rozalski, M., \& Skiba, R. J. (2017). The need for school-based mental health services and recommendations for implementation. School Mental Health, 9(3), 205-217. https://doi.org/10.1007/s12310-017-9216-5

21. Kirkpatrick, D., \& Kirkpatrick, J. (2006). Evaluating training programs: The four levels. Berrett-Koehler Publishers.

22. Kutcher, S., Gilberds, H., Morgan, C., Greene, R., Hamwaka, K., \& Perkins, K. (2015). Improving Malawian teachers' mental health knowledge and attitudes: An integrated school mental health literacy approach. Global Mental Health, 2, E1. https://doi.org/10.1017/gmh.2014.8

23. Lawson, H. A., Caringi, J. C., Gottfried, R., Bride, B. E., \& Hydon, S. P. (2019). Educators' secondary traumatic stress, children's trauma, and the need for trauma literacy. Harvard Educational Review, 89(3), 421-447. https://doi.org/10.17763/1943-5045-89.3.421

24. Martin, B. (2020, May 18). The Santa Fe high school shooting's uncounted victims. Texas Monthly. Available from: https://www.texasmonthly.com/politics/santa-fe-high-school-shooting-two-yearslater/

25. Mclnerny, C. (July 3, 2018). As teen suicide rates climb, Texas Legislators discuss mental health services in schools. Houston Public Media. https://www.houstonpublicmedia.org/articles/news/2018/07/03/294101/as-teen-suicide-ratesclimb-texas-legislators-discuss-mental-health-services-in-schools/ 
26. Moon, J., Williford, A., \& Mendenhall, A. (2017). Educators' perceptions of youth mental health: Implications for training and the promotion of mental health services in schools. Children and Youth Services Review, 73, 384-391. https://doi.org/10.1016/j.childyouth.2017.01.006

27. Ohrt, J. H., Deaton, J. D., Linich, K., Guest, J. D., Wymer, B., \& Sandonato, B. (2020). Teacher training in K-12 student mental health: A systematic review. Psychology in the Schools, 57(5), 833-846. https://doi.org/10.1002/pits.22356

28. Reker, K. (2016). Trauma in the classroom: Teachers' perspectives on supporting students experiencing child traumatic stress. Dissertations. 2146. https://ecommons.luc.edu/luc_diss/2146/

29. Sale, E., Hendricks, M., Weil, V., Miller, C., Perkins, S., \& McCudden, S. (2018). Counselling on access to lethal means (CALM): An evaluation of a suicide prevention means restriction training program for mental health providers. Community Mental Health Journal, 54(3), 293-301. https://doi.org/10.1007/s10597-017-0190-z

30. Schonert-Reichl, K. A. (2017). Social and emotional learning and teachers. The Future of Children, $27(1), 137-155$.

31. Sharma, S. V., Chuang, R., Rushing, M., Naylor, B., Ranjit, N., Pomeroy, M., \& Markham, C. (October 2020). Social determinants of health-related needs during COVID-19 among low-income households with children. Preventing Chronic Disease, 17, E119. http://dx.doi.org/10.5888/pcd17.200322

32. Substance Abuse and Mental Health Services Administration. (2014). SAMHSA's concept of trauma and guidance for a trauma-informed approach. https://store.samhsa.gov/product/SAMHSA-sConcept-of-Trauma-and-Guidance-for-a-Trauma-Informed-Approach/SMA14-4884

33. Ursachi, G., Horodnic, I. A., \& Zait, A. (2015). How reliable are measurement scales? External factors with indirect influence on reliability estimators. Procedia Economics and Finance 20,679-686. https://doi.org/10.1016/S2212-5671(15)00123-9

34. Wei, Y., \& Kutcher, S. (2014). Innovations in practice: 'Go-to' educator training on the mental health competencies of educators in the secondary school setting: A program evaluation. Child and Adolescent Mental Health, 19(3), 219-222. https://doi.org/https://doi.org/10.1111/camh.12056

35. World Health Organization, (2016). Mortality Database. World Health Organization. 